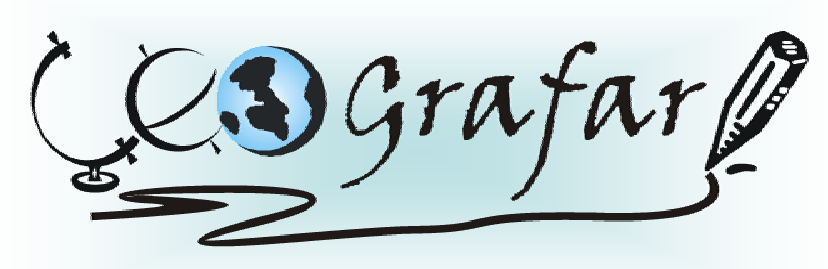

Revista Eletrônica do Programa de Pós-Graduação em Geografia - UFPR

\title{
A PRODUÇÃO E GERENCIMAENTO DOS RESÍDUOS SÓLIDOS EM CURITIBA (PR) E AS ALTERNATIVAS DE CONTRIBUIÇÃO COM O MEIO AMBIENTE
}

\author{
NILZA APARECIDA DA SILVA OLIVEIRA ${ }^{1}$
}

Resumo: O artigo trata exclusivamente sobre a forma de gerenciamento dos resíduos sólidos em Curitiba-pr, destacando as várias alternativas utilizadas para isto, bem como, salienta a necessidade de mudanças de hábito dos cidadãos para a contribuição na melhoria da qualidade de vida. A pesquisa foi realizada, tendo como fundamentação teórica às entidades dos órgãos públicos de Curitiba, bem como outros órgãos do governo que fornecem subsídios sobre o assunto.

Palavras-Chave: resíduos sólidos, gerenciamento e qualidade de vida

\begin{abstract}
The article deals exclusively on how to manage solid waste in Curitiba-pr, highlighting the various alternatives used to this, and stresses the need to change habits of the people for the contribution in improving the quality of life. The survey was conducted, with the theoretical foundation of the public entities of Curitiba, as well as other organs of the government providing subsidies on the subject.
\end{abstract}

Key-words: solid waste, management and quality of life

\section{INTRODUÇÃO}

Através das novas técnicas de industrialização, do aumento populacional e da febre de consumo que impera no mundo, onde cada pessoa busca incansavelmente satisfazer seus desejos e necessidades, estamos transformando cada vez mais recursos naturais em bens de consumo. E, nesse processo geramos de forma direta e indireta uma série de resíduos e criamos uma situação, que se não adotarmos medidas que visem a redução, a reutilização e a reciclagem desses resíduos, em pouco tempo não teremos mais recursos naturais necessários à produção de novos bens de consumo e transformaremos o mundo em um verdadeiro lixão.

A preocupação daqueles que habitam o meio urbano cresce a cada dia, pois os humanos sabem que o meio ambiente precisa de cooperação para produzir e fornecer qualidade de vida para a humanidade. Desta forma torna-se imprescindível saber que existem várias maneiras de diminuir o impacto ambiental e, sobretudo no que diz respeito aos resíduos sólidos, que

\footnotetext{
${ }^{1}$ E-mail: nilollyve@yahoo.com.br
} 
aumenta a cada dia, como resultado das atividades humanas no meio. No contexto atual é inegável a necessidade de se pensar na resolução desse problema.

Um grande número de localidades urbanas e rurais, em todo mundo, vem sofrendo transformações ambientais danosas decorrentes dos crescimentos populacionais, industriais e da oferta de bens de consumo descartáveis, gerando o lixo e resíduos industriais diversos, que necessitam cada vez mais de vazadouros e/ou aterros sanitários para sua disposição, muitas das vezes inadequadas a esse fim. Sem a infra-estrutura necessária para oferecer a destinação adequada aos resíduos sólidos, muitos dessas áreas tornam-se freqüentemente soluções improvisadas ou emergenciais, que acabam por se transformarem em definitivas, gerando uma série de transtornos que por vezes se refletem em problemas graves de saúde pública.

De acordo com o IBGE/IPPUC (2002), o total de lixo gerado nos centros urbanos, calcula-se que algo entre $35 \%$ e $45 \%$ do que vai parar nos aterros sanitários, lixões controlados ou lixões a céu aberto, são compostos por materiais não degradáveis que podem ser reaproveitados. São resíduos que ocupam grandes espaços, enquanto que as áreas destinadas aos aterros estão cada vez mais escassas. Se continuar neste ritmo acelerado de geração de resíduos, segundo estatísticas, a montanha de lixo sobre a terra em 2.050 deverá chegar a um trilhão e 500 bilhões de toneladas.

São produzidas 241.614 toneladas de lixo diariamente no país, destes 54\% são lançados a céu aberto, $16 \%$ em aterros controlados, $13 \%$ destina-se ao aterro sanitário, $7 \%$ vai para o aterro de resíduos especiais, 2\% para a usina de compostagem, 5\% para a reciclagem e apenas 3\% é destinado para a incineração (IBGE, 2002).

A reciclagem do lixo, embora seja uma das mais vitais iniciativas para a defesa do meio ambiente, exige uma mobilização profunda e envolve a mudança de comportamentos ativos, de amplos setores da sociedade. Diante dessa problemática, os administradores da cidade de Curitiba vêm procurando fazer a sua parte, tornando a iniciativa um exemplo para outras cidades.

\section{LOCALIZAÇÃO DE CURITIBA (PR)}

O Município de Curitiba foi criado e instalado em 29 de março de 1693, sendo desmembrado de Paranaguá. Sua denominação está ligada à quantidade de pinheiros existentes anteriormente nesta área 
A capital do Estado do Paraná, que é Curitiba, tem 313 anos, e está localizada no Sul do Brasil. É uma cidade reconhecida internacionalmente pelo intenso marketing, desenvolvido no planejamento urbano e qualidade de vida. Diante disso ficou conhecida por diferentes slogans como: Cidade de $1^{\circ}$ mundo, Cidade Sorriso, capital Ecológica, Capital Social, etc.

Sua localização está entre as coordenadas, 2524’40 “S, e 4996’23” W, apresenta altitude média de 934,6 metros, possui uma área de 432,17 Km2.

A maior parte de sua população de 1,6 milhões de habitantes descende de imigrantes italianos, poloneses, alemães, ucranianos, japoneses, sírios, libaneses e portugueses. Curitiba está dividida em vários bairros, perfazendo um total de 75.

\section{FIGURA 01- CARACTERIZAÇÃO GEOGRÁFICA DA ÁREA}

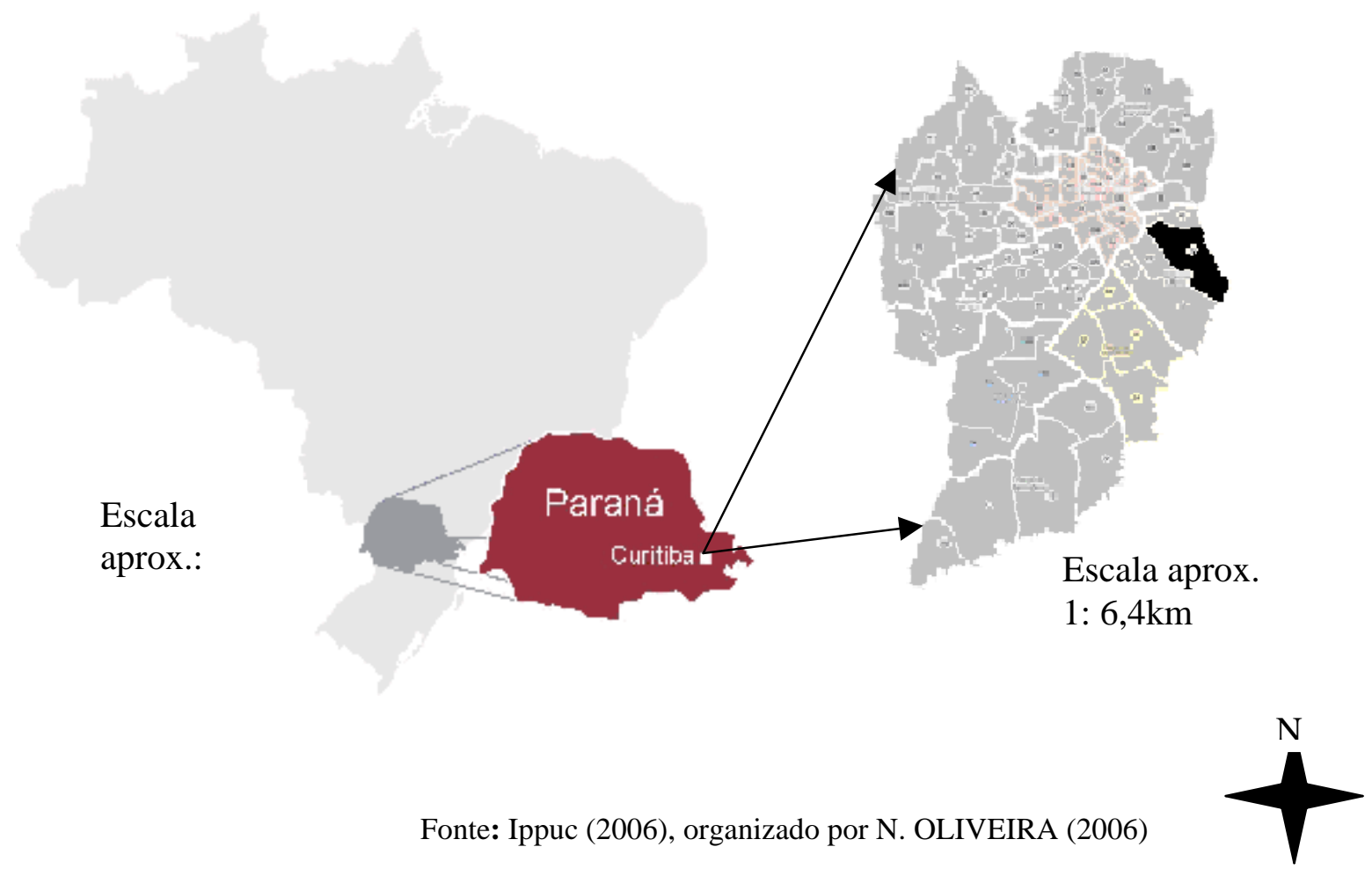

\section{O HISTÓRICO DA PRODUÇÃO E GERENCIAMENTO DOS RESÍDUOS SÓLIDOS EM CURITIBA (PR)}

O Município de Curitiba e Região Metropolitana antes da implantação do Aterro Sanitário, não possuíam um local adequado para a disposição de Resíduos Sólidos Urbanos (lixo). A cidade utilizava depósitos de lixo (lixões) da Lamenha Pequena - CIC e de São José dos Pinhais que teve uma vida útil de apenas seis meses. Os lixões foram desativados, sendo 
que o da Lamenha Pequena e de São José dos Pinhais foram recuperados e hoje estão na condição de aterros controlados.

Em 20 de novembro de 1989, iniciou-se a operação do Aterro Sanitário, localizado ao sul do Município de Curitiba a 23 km do centro, no bairro da Cachimba, localizado entre os municípios de Araucária e Fazenda Rio Grande. A área total do Aterro Sanitário é de $410.000 \mathrm{~m}^{2}$, sendo que a área destinada à disposição de lixo é de $237.000 \mathrm{~m}^{2}$. O Aterro Sanitário da Cachimba recebe resíduos de 14 municípios da Região Metropolitana, a saber: Almirante Tamandaré, Araucária, Campina Grande do Sul, Campo Largo, Campo Magro, Colombo, Contenda, Fazenda Rio Grande, Itaperuçu, Pinhais, Piraquara, São José dos Pinhais, Mandirituba e Quatro Barras.

Para escolha deste local, a Prefeitura Municipal de Curitiba, fundamentada em estudos preliminares e normas operacionais, certificou-se que a confinação dos resíduos sólidos seria segura em termos de controle de poluição ambiental e proteção ambiental. Foi adotada em projeto uma produção "per capta" média de lixo de 0.55 kg/hab/dia, e uma abrangência variável do sistema de coleta de 75 a 90\%, nos anos de 1988 a 2010.

Considerando-se a capacidade aproximada de projeto do aterro de 3.239 .500 toneladas, e a projeção populacional para o município de Curitiba, estimou-se uma vida útil aproximada de 11 anos e cinco meses.

Em 20 de novembro de 1989, iniciou-se a operação do Aterro Sanitário da Cachimba. Até maio/96, depositamos a quantidade de 2.173.634.66 toneladas de Resíduos Sólidos (www.curitiba.pr.gov.br).

\section{Como se dá o processo da Reciclagem}

Há alguns anos atrás, pensava-se que o problema do lixo seria resolvido com a reciclagem. Hoje se sabe que a solução está no Gerenciamento Integrado do Lixo, assim a reciclagem é apenas uma das formas de trabalhar a questão do lixo.

A reciclagem trata o lixo como matéria-prima a ser reaproveitada para fazer novos produtos. Através a coleta seletiva é feita à separação dos recicláveis, ainda nos domicílios, pela população. O recolhimento dos materiais separados é feito por caminhões da prefeitura nas próprias residências, ou entregues pela população nos pontos de entrega, que são as (PEV) Ponto de Entrega Voluntária, que possui tambores de várias cores, destinados a determinados 
tipos de resíduos, como pode ser observado (figura 05), estes são colocados em locais públicos e de fácil acesso.

\section{FIGURA 02 -TAMBORES UTILIZADOS NA COLETA SELETIVA DO LIXO}
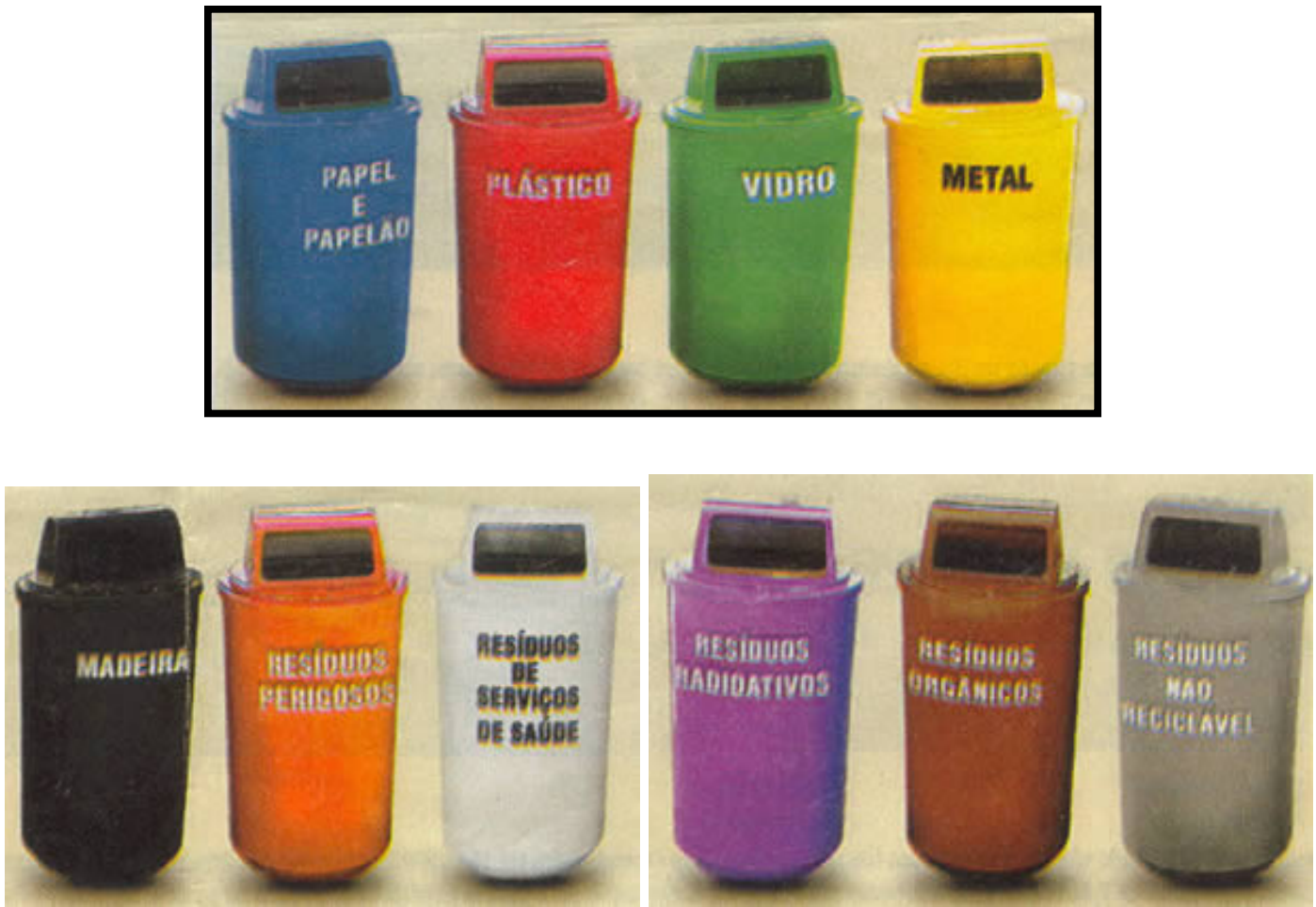

Fonte: Cempre (2000)

O material recolhido é encaminhado para a central de triagem para separação, classificação e venda. Para o sucesso da coleta seletiva o engajamento da população é essencial, sendo necessário um trabalho muito bem estruturado de Educação Ambiental. A separação dos recicláveis ainda no domicílio tem sido apontada como o modo mais efetivo para manter os materiais mais limpos e menos contaminados por outros tipos de lixo.

A vantagem da coleta seletiva é o desafogamento e o aumento de vida útil dos aterros sanitários, pois o material recolhido retorna ao processo produtivo além de colaborar com a geração de renda que contribui com a qualidade de vida dos catadores. Esse processo envolve a população que se sente também responsável pela resolução dos problemas provocados pelo acúmulo de lixo, o que significa uma conscientização ambiental na sociedade (www.curitiba.pr.gov.br) 


\section{O programa da coleta seletiva}

O programa de coleta seletiva de Curitiba já existe há vários e atinge praticamente 100\% da cidade sendo conhecido como "O Lixo que Não é Lixo". A coleta acontece de três formas diferentes: pela prefeitura, com sua frota de caminhões verdes (Figura 03); pelos coletores de material reciclável que integram a Cooperativa dos Coletores de Material Reciclável (Recopere) e ainda a Coleta Especial de Resíduos que cuida do lixo mais perigoso, como pilhas, lâmpadas, embalagens de remédios e de produtos químicos. A face mais criativa do sistema ambiental da cidade é, sem dúvida, a Usina de Valorização de Rejeitos, situada em Campo Magro, município da grande Curitiba, dentro da Fazenda Solidariedade. Ali o lixo é separado e preparado para a reciclagem. O papel é encaminhado às indústrias papel eiras, o ferro é levado para siderúrgicas, o vidro transparente vai para as cristaleiras, o vidro colorido para as fábricas de garrafas e artefatos deste material, o alumínio para as indústrias de metais não-ferrosos e as garrafas plásticas seguem para diferentes indústrias de reprocessamento. Com este projeto o governo municipal conseguiu vários resultados. Um deles, a geração de empregos, com funcionários em dois turnos tocando a usina 14 horas por dia. Outro aspecto é o da economia de recursos, uma vez que a usina propicia novos produtos do que foi descartado pela sociedade. Há também os dividendos com a venda do material e por fim o aspecto mais importante, a educação ambiental. Quem trabalha na usina e quem visita o local aprende, na prática a preservar o meio ambiente, porque percebe a importância da limpeza, da organização e da reciclagem. E todas as dúvidas são esclarecidas por uma educadora ambiental que recebe e orienta os visitantes.

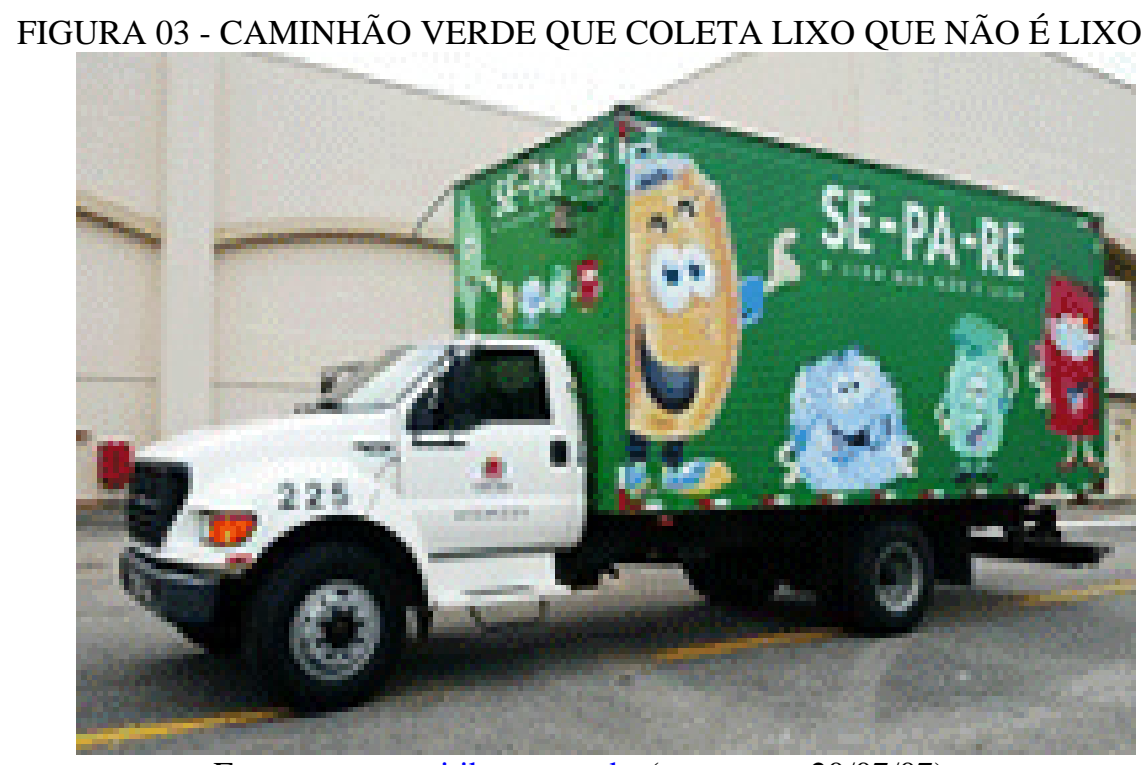

Fonte: www.curitiba.pr.gov.br (acesso em 20/07/07) 


\section{A contribuição dos carrinheiros no processo da coleta seletiva}

Os responsáveis por evitar um colapso no problema do lixo em Curitiba são pobres, moram geralmente em favelas e raras vezes conseguem ganhar mais do que R \$ 10 por dia. Trabalham todos os dias, sem direito a férias, feriados ou Fundo de Garantia. Agora, apoiados pelo Ministério Público do Trabalho, os catadores de papel estão tentando fazer seu serviço ter a devida atenção do poder público. Querem se organizar para sair da penúria e ter direitos mínimos, como a aposentadoria. Estimativas da Prefeitura de Curitiba mostra que os catadores de papel - ou carrinheiros (figura 04 05) como são conhecidos em Curitiba retiram das ruas da cidade cerca de 370 toneladas de lixo reciclável por dia. É mais do que o dobro do que a própria prefeitura consegue fazer e suficiente para movimentar cerca de R\$ 780 mil por mês. São cinco Associações de carrinheiros na capital paranaense, que fazem a coleta, separação de material, depois a venda do que recolhem e, partilham os ganhos entre todos. No entanto os catadores não vendem tudo que recolhem, só vendem aquilo que interessa ao comprador, o que não interessa é descartado e acaba indo para o aterro sanitário. Segundo a prefeitura de Curitiba, eles são 5 mil associados. Porém, existe também os catadores informais, que não são filiados a nenhuma associação, segundo as estimativas da Secretaria Municipal do Meio ambiente, existe cerca de 15 mil catadores no total. Eles chegam a caminhar, puxando seus carrinhos, 35 quilômetros todos os dias. O trabalho dos catadores evita que aumente ainda mais o problema de espaço para continuar depositando todo o lixo dos 1,6 milhão de habitantes da capital. Em Curitiba, o problema do destino do lixo é grave, e obrigou o município a prorrogar por um ano a vida útil do aterro sanitário da Cachimba.

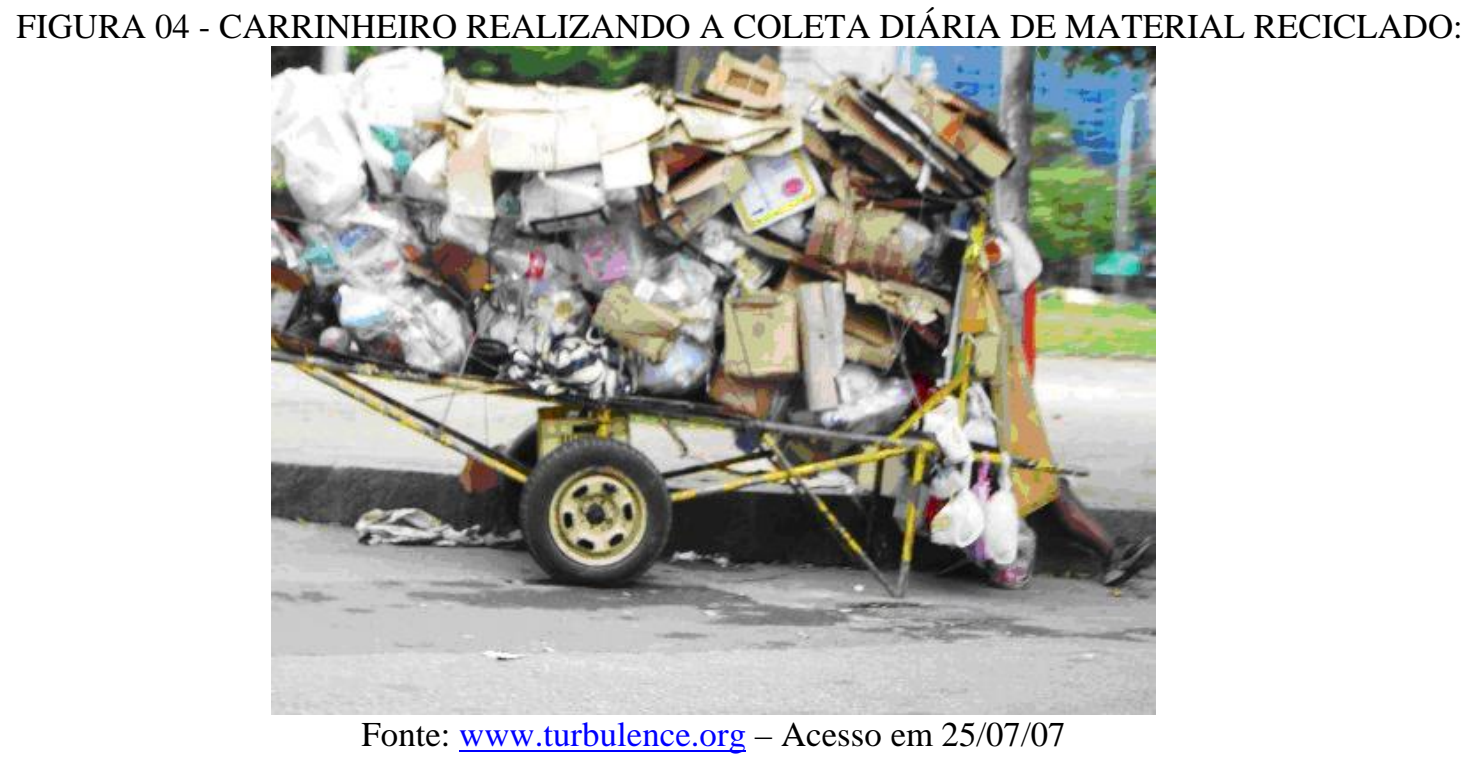




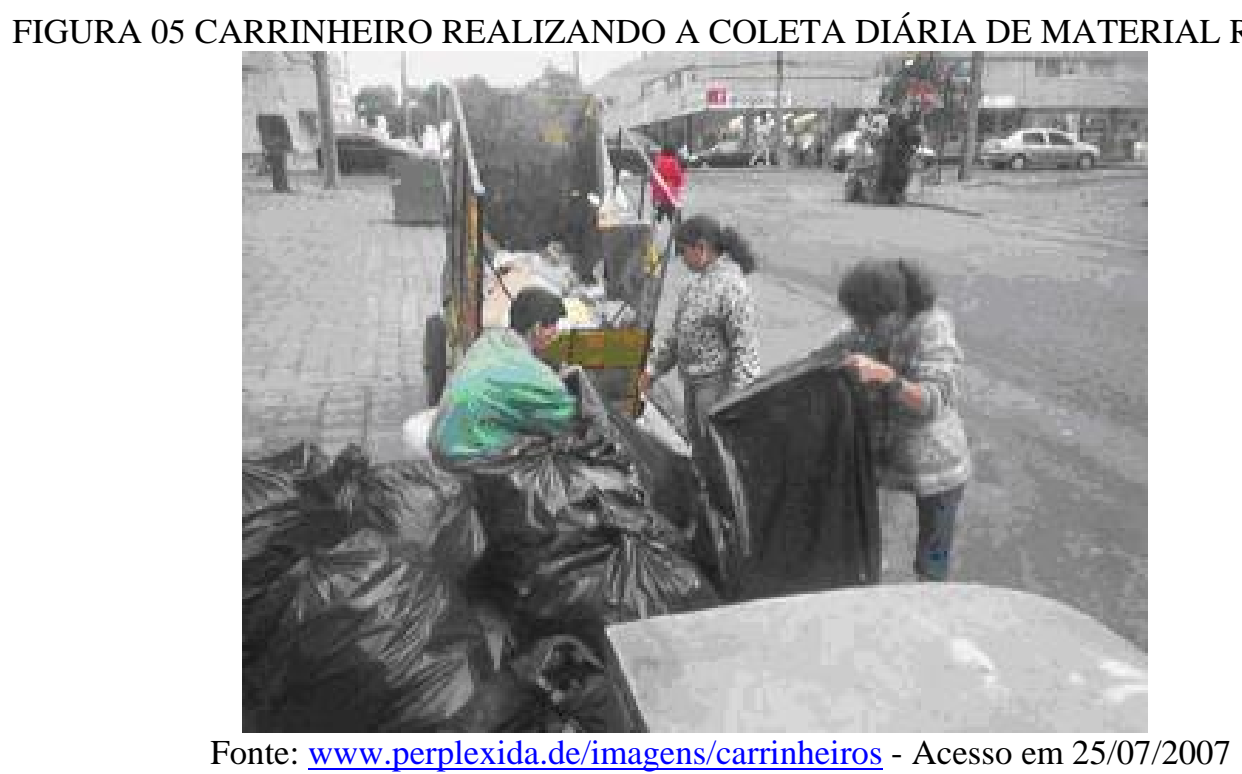

\section{Reciclagem de lixo poupa árvores e contribui para projetos sociais}

A Usina de Valorização de Rejeitos (UVR), administrada pelo Instituto Pró-Cidadania de Curitiba (IPCC) em Campo Magro (Figuras 06) processou neste ano 3.581 .409 quilos de lixo reciclável, que representa uma economia de 30 dias em área no aterro sanitário. O material obtido com a triagem e a separação do lixo é prensado e vendido, por quilo, a empresas de reciclagem. Com os recursos obtidos, o IPCC faz a compra de produtos como fraudas geriátricas, materiais e uniformes escolares, kits construções, cestas básicas e outros, que são entregues às instituições parceiras do IPCC em programas sociais desenvolvidos no município. "O curitibano tem em sua cultura a separação do lixo.

Esta “ação consciente se reverte em benefícios sociais e de proteção ao meio ambiente”, diz a presidente do IPCC, Fernanda Richa. O reaproveitamento de produtos na usina evitou o corte de 74.204 árvores e a utilização de 244.420 quilos de bauxita. Do lixo recebido na usina, são recuperados livros e objetos que permitem atualizar uma biblioteca e um museu que funcionam no local e são abertos à visitação pública. Lá, podem ser encontradas algumas curiosidades, como escafandros, dentaduras, óculos, rádios e móveis de valor histórico, entre outros. O espaço é utilizado como fonte de informações e onde são desenvolvidas atividades de educação ambiental e de sensibilização aos visitantes quanto à importância da reciclagem e preservação dos recursos naturais. A Usina de Valorização de Recicláveis foi criada para triagem e comercialização de parte dos resíduos sólidos reaproveitáveis, coletados pelo do programa "Lixo que não é lixo", da Prefeitura de Curitiba. O programa incentiva a separação de orgânicos, papéis, plásticos, vidros e metais em recipientes diferenciados. A coleta seletiva 
teve um aumento de 43\% em 2006. Para suprir a demanda, o IPCC promove melhorias na infra-estrutura da usina. O trabalho de triagem do lixo é feito por 78 funcionários.

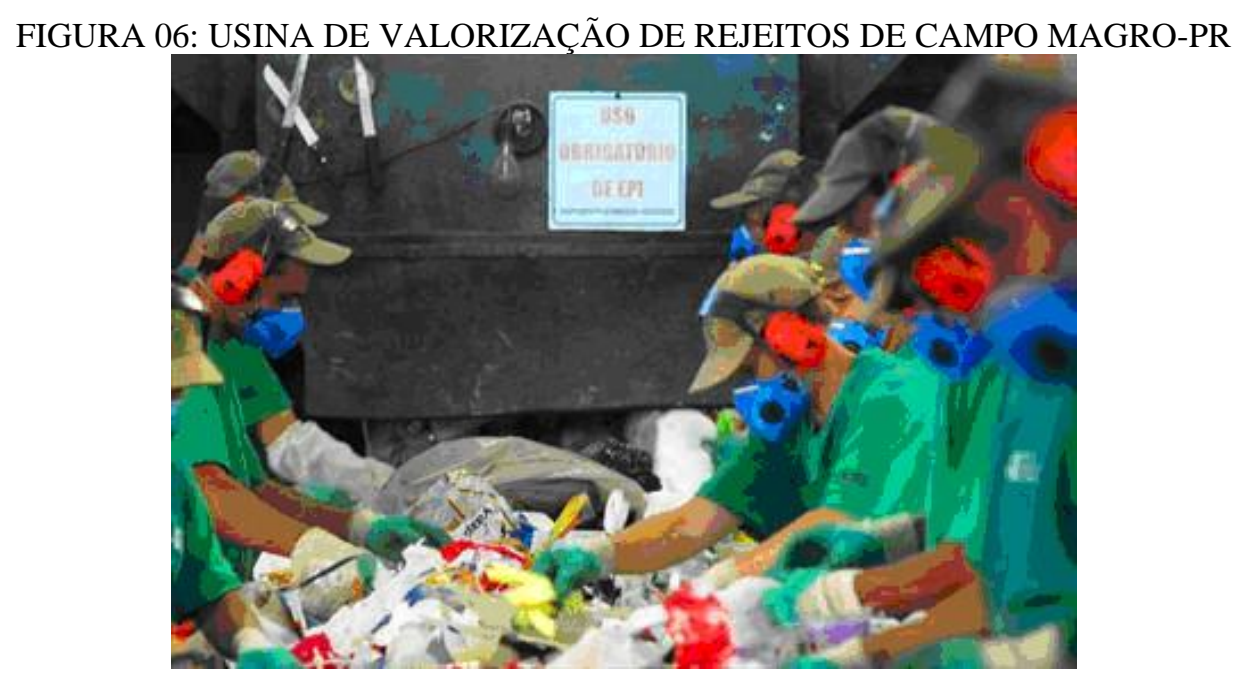

Fonte: www.curitiba.pr.gov.br - Acesso em 20/07/07

\section{PROGRAMA “COMPRA DO LIXO”}

Segundo informações do Instituto de Pesquisas Públicas de Curitiba IPPUC (2005), a Prefeitura Municipal de Curitiba em 31 de janeiro de 1989, implantou o Programa "Compra do Lixo", em áreas onde havia seríssimos problemas ambientais devido à falta de coleta de lixo. A principal causa desta deficiência era em função das áreas serem desurbanizadas e de difícil acesso aos de encostas de morros, fundos de vale e favelas com ruas muito estreitas.

O Programa Compra do Lixo, constitui-se numa forma alternativa, caminhões da coleta por tratar de Coleta domiciliar, destinada a atender as camadas menos favorecidas da população.

Uma equipe de Educação Ambiental da Prefeitura entra em contato com a comunidade, com objetivo de organizá-la. Criada a Associação de Moradores, é firmado um convênio entre Prefeitura e Comunidade, a qual se torna responsável pela distribuição dos sacos plásticos e pelo controle do número de sacos depositados na caçamba por família participante do Programa. A Prefeitura instala uma caçamba estacionária com capacidade de $7 \mathrm{~m} 3$ em local previamente determinado, e entrega à Associação, quinzenalmente, sacos de lixo com capacidade de 60 litros para captação e acondicionamento dos resíduos.

Para cada saco de lixo contendo de 8 a $10 \mathrm{~kg}$ de resíduos depositados na caçamba, o participante recebia um vale-transporte. A partir de julho de 1991, a Prefeitura, visando 
auxiliar os pequenos produtores da Região Metropolitana de Curitiba e Litoral, passa a adquirir o excedente de suas safras através do convênio firmado com a FEPAR - Federação Paranaense das Associações dos Produtores Rurais. Naquele momento substituímos o valetransporte por produtos hortifrutigranjeiros da época.

A Associação de Moradores, pelo trabalho de parceria com a Prefeitura, recebe $10 \%$ do valor pago por cada saco de lixo depositado na caçamba. Este dinheiro é depositado em conta corrente bancária em nome da Associação, que utiliza este recurso em obras ou serviços definidos pela própria comunidade.

\section{Benefícios do Programa:}

- Limpeza total de áreas a curto prazo, diminuindo sensivelmente a incidência de doenças causadas por vetores;

- nos locais onde havia depósitos de lixo a céu aberto, as comunidades utilizaram este espaço para execução de hortas comunitárias;

- possibilitou o manejo correto dos resíduos e seu devido acondicionamento, evitando a exposição do lixo, mesmo durante os intervalos de coleta;

- maior integração cidadão município na solução dos problemas da comunidade;

- Auxílio no escoamento da safra dos hortigranjeiros produzidos na região metropolitana de Curitiba e litoral, e

- Enriquecimento da alimentação das famílias mais carentes de nossa comunidade.

\section{O PROGRAMA CÂMBIO VERDE}

O Programa Câmbio Verde nasceu de uma derivação do Programa Compra do Lixo e do Programa Lixo que não é Lixo. E consiste na troca de material reciclável por produtos hortigranjeiros de época.

Em junho de 1991, houve uma super safra de produtos hortigranjeiros na Região Metropolitana de Curitiba e face à grande quantidade de produtos, os pequenos produtores encontraram dificuldades para a comercialização de suas safras e muitos estavam transformando sua produção em adubo orgânico e alimento para criações. 
Diante daquela realidade o poder público de maneira criativa e de baixo custo, resolveu auxiliar os pequenos produtores no escoamento de suas safras. Para tanto, firmou convênio com a FEPAR - Federação Paranaense das Associações dos Produtores Rurais, e passou adquirir o excedente da produção e repassar estes produtos às famílias com renda salarial entre 0 a 3,5 salários mínimos.

O cambio verde tem como objetivos:

- Promover o escoamento da safra de produtos hortigranjeiros dos pequenos produtores de Curitiba e da Região Metropolitana;

- Criar na população o hábito de separar o lixo orgânico do inorgânico;

- Sensibilizar a comunidade para a correta destinação final dos resíduos;

- Reforçar a alimentação da camada menos favorecida de nossa sociedade.

A troca de materiais reciclados por alimentos, depende da quantidade de reciclados que o indivíduo tiver; funcionando da seguinte forma:

- entre 01 e $04 \mathrm{Kg}$ de materiais reciclados, equivalem a uma sacola de alimentos, no valor de 0,53(cinqüenta e três centavos), contendo alimentos de uma única espécie;

- com $5 \mathrm{Kg}$ ou mais de materiais reciclados, equivalem a uma sacola de alimentos, com produtos variados, a cada cinco(cinco) Kg, recebe uma sacola equivalendo a 0,53(cinqüenta e três centavos).

Na figura 07 observa-se o funcionamento da campanha de compra do lixo.

FIGURA 07-POSTO DE TROCA DE MATERIAIS RECICLADOS POR ALIMENTOS

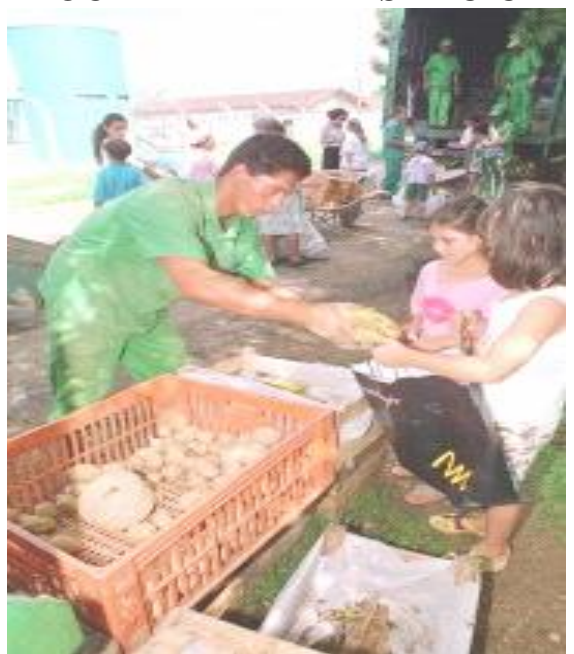

Fonte: www.curitiba.pr.gov.br, acesso em 23/02/2007 


\section{COMO FUNCIONA UM ATERRO SANITÁRIO}

Segundo a sociedade americana dos Engenheiros Civis (ASCE), o Aterro Sanitário é definido como sendo "uma técnica para disposição final dos resíduos sólidos no solo, sem causar nenhum prejuízo ao meio ambiente, e sem causar dano ou perigo à saúde e à segurança pública, técnica esta que utiliza princípios de engenharia para acumular o resíduo sólido na menor área possível, reduzindo seu volume ao mínimo e cobrindo-o com uma camada de terra com a freqüência necessária, pelo menos ao fim da cada dia”.

Existe uma grande diferença entre lixão e aterro sanitário. No aterro, o lixo é disposto em trincheiras, abertas no solo, sendo coberto diariamente com terra, após compactação com tratores de esteira. Antes da colocação do lixo, o solo é impermeabilizado com $50 \mathrm{~cm}$ de argila compactada e membranas plásticas, para evitar que o chorume contamine os lençóis freáticos. Os gases (metano, CO2, dioxinas, etc., também gerados na composição da matéria orgânica, são drenados e queimados nos próprios drenos coletores de gases. Esses drenos são formados por tubos de concreto com 20 centímetros de diâmetro, cheios ou não de pedra britada, aos quais vão sobrepondo outros tubos à medida que o aterro cresce (Cempre 2000).

De acordo com as pesquisas existentes o aterro sanitário é a melhor e mais barata forma de gerenciamento de resíduos sólidos, diante disso, o poder público da cidade de Curitiba está investindo maciçamente neste setor.

Observa-se nas figuras 08 e 09 a construção do aterro sanitário de Curitiba.

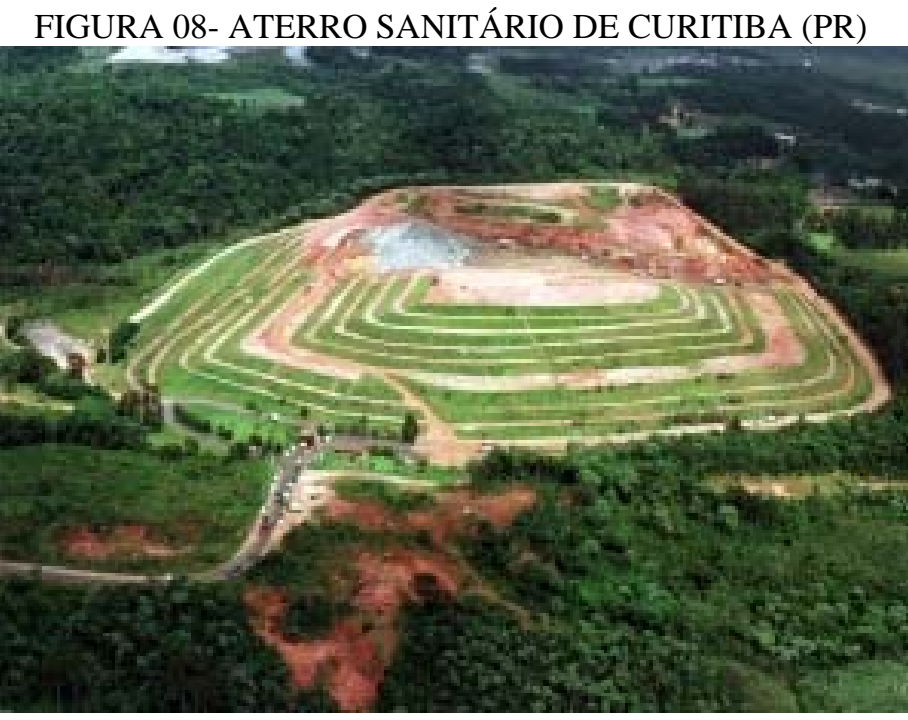

Fonte: www.curitiba.pr.gov.br, acesso em 23/02/2007

FIGURA 09- ATERRO SANITÁRIO DE CURITIBA-PR 


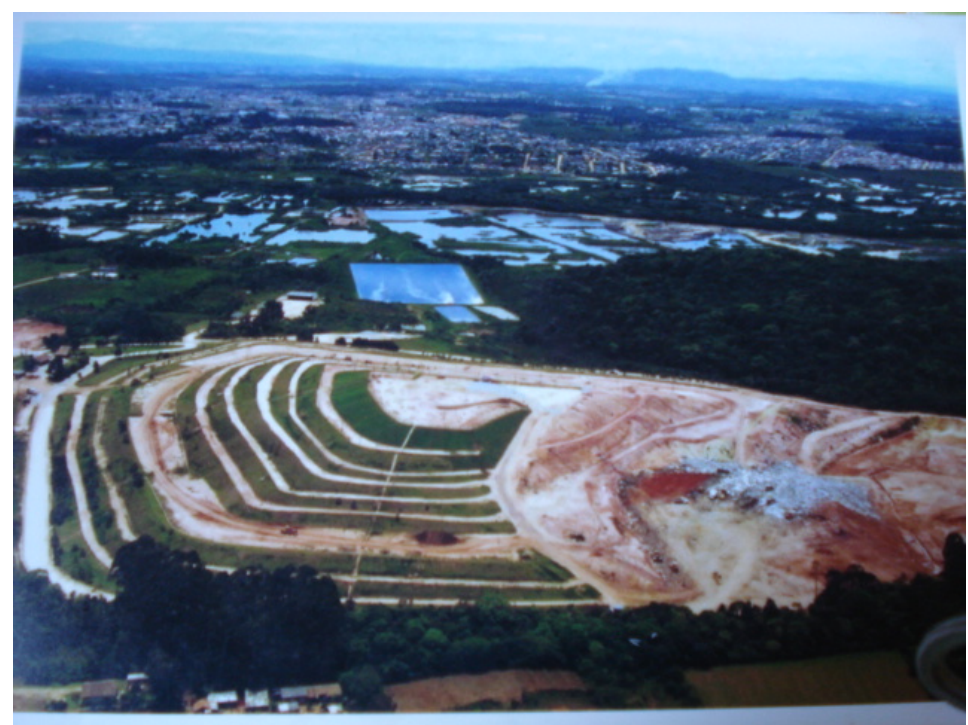

Fonte: www.curitiba.pr.gov.br, acesso em 23/02/2007

\section{CONSIDERAÇÕES FINAIS}

Dentre as técnicas apresentadas para destinação final dos resíduos, e que vem de encontro à Legislação e a realidade da situação sócio-econômica dos municípios paranaenses é a forma de aterro sanitário, que em comparação à outras técnicas de gerenciamento de resíduos, apresenta um baixo custo, estando assim ao alcance dos municípios paranaenses, sendo assim, a técnica mais recomendada atualmente no país.

A administração do lixo é hoje uma das grandes preocupações na organização urbana, e Curitiba está realizando um trabalho bastante significativo para com a população e o meio ambiente.

O lixo brasileiro é considerado um dos mais ricos do mundo, e sua reciclagem é fortemente sustentada pela catação informal.

O planeta atingiu neste ano, a marca de seis bilhões de habitantes, e este enorme contingente populacional terá de procurar sobrevivência em um mundo em que a deterioração do meio ambiente é um fato presente e uma realidade dolorosa. A degradação da condição humana é considerada sobretudo, nas grandes cidades. Estará o homem do terceiro milênio, da era da modernidade, preparado para o desafio de resolver os desequilíbrios ambientais e assegurar uma qualidade mínima de vida? Estará ele capacitado para realizar tarefas aparentemente simples, como a de dar destinação adequada ao lixo produzido por todos os cantos do planeta? 
Fica aqui então o nosso questionamento e que cada um faça uma reflexão sobre o seu papel enquanto ser humano dentro do meio.

\section{BIBLIOGRAFÍA:}

ANDRADE R.L. Coleta Seletiva de lixo na cidade de Cruzeiro do Oeste-Pr. X Qualidade de vida. Florianópolis: UFSC (Dissertação de Mestrado) 2002.

AZEVEDO, J. Informações estatísticas dos resíduos sólidos urbanos no Brasil e em algumas das suas capitais http://www.jornaldomeioambiente.com.br, pesquisa em 15/08/07.

BERRIOS, M. R. O lixo domiciliar. A produção de resíduos sólidos residenciais em cidades de porte médio e a organização do espaço: o caso de Rio Claro - SP. Dissertação de Mestrado. Instituto de Geociências e Ciências Exatas. Universidade Estadual Paulista "Julio de Mesquita Filho”. Rio Claro, 1986.

CAPRA, F. A. A teia da vida: uma nova compreensão cientifica dos sistemas vivos. São Paulo: Cultrix, 1996.

CEMPRE. [En de Línea]. São Paulo: Comissão para a reciclagem, 2006 da empresa. $<$ http://www.cempre.org.br/>. [04 de janeiro de 2007].

CERDEIRA Rizzo, C. P. A percepção do lixo na perspectiva de diferentes atores sociais no ambiente urbano de Paranaguá: Curitiba, UFPR (Tese de Doutorado) 1999.

COMPROMISSO empresarial para reciclagem. Manual de Gerenciamento Integrado do Lixo. São Paulo: Cempre, 2000.

DEPARTAMENTO de Limpeza Urbana - LIMPURB. São Paulo, 2004. Disponível em: www.prefeitura.sp.gov.br/secretarias/servicoseobras/limpurb. Acesso em 15/10/06.

DIAS, G.F. Educação Ambiental: princípios e práticas. 3. ed. São Paulo; Gaia, 1994.

GALINO, W. R. E J. Heróis da reciclagem. Jornal Gazeta do Povo, 11 de Julho de 2002. www.ana.gov.br \{[acesso em 28 de julho de 2007].

GRIPPI, S. Lixo, reciclagem e sua história: guia para as prefeituras brasileiras. Rio de Janeiro, Interferência, 2001.

IBGE, censo demográfico 2000, www.ibge.gov.br. [Acesso em 10 de janeiro de 2007].

IPPUC, instituto da investigação de Curitiba, local www.ippu.pr.gov.br, [acesso em 12 de janeiro de 2007].

INSTITUTO BRASILEIRO DE GEOGRAFIA E ESTATÍSTICA. IBGE - Pesquisa Nacional de Saneamento Básico. Brasília: 2002.

JACOBI, P. R. Cidade e Meio ambiente: Percepções e prática em São Paulo. São Paulo: annablume, 2000.

LOIOLA, M. Não é lugar de lixo. Disponível em http://www.riosvivos.org.br/canal.php?canal=167\&mat_id=7333, pesquisa em 15/08/07.

OLIVEIRA, N.A. A percepção dos resíduos sólidos (lixo) de origem domiciliar no bairro Cajuru em Curitiba-Pr- um olhar reflexivo a partir da educação ambiental. Dissertação de Mestrado. Departamento de Geografia da Universidade Federal do Paraná. Curitiba, 2006. 
PREFEITURA MUNICIPAL DE CURITIBA. Curitiba em bairros. www.curitiba.pr.gov.br, [aceso em 10 de fevereiro de 2007].

ZIGLIO, L. O mercado da reciclagem de papel no município de São Paulo. In: Scripta Nova: revista eletrônica de Geografía e Ciências Sociales. Universidade de Barcelona, Vol. VI, nº 119, Agosto/2002. Disponível em: http://www.ub.es/geocrit/sn/sn199-33.htm, acesso em 20/10/2004.

Site consultado: www.pr.gov.br/sema- Consulta em 18/08/07 